\title{
Myomectomy in early pregnancy-a case report
}

Received: 4 February 2006 / Accepted: 24 May 2006 / Published online: 8 July 2006

(C) Springer-Verlag Berlin / Heidelberg 2006

\begin{abstract}
Uterine leiomyomas are by far the most common benign tumours of the female genital tract. The true incidence of leiomyomas during pregnancy is, however, unknown. Although leiomyomas usually remain asymptomatic during pregnancy, they may complicate its course. The management of leiomyoma during pregnancy is medical, but, in rare circumstances, surgical intervention and myomectomy may be required. A case of myomectomy in early pregnancy is described.
\end{abstract}

Keywords Leiomyoma · Myomectomy · Pregnancy

Uterine leiomyomas are by far the most common benign tumours of the female genital tract. The prevalence rates vary from $20-50 \%$ of women, depending on age, ethnicity, parity and method used to assess their presence [1]. The true incidence of leiomyomas during pregnancy is, however, unknown, but reported rates vary from as low as $0.1 \%$ of all pregnancies to higher rates of $12.5 \%$ [2].

Although leiomyomas usually remain asymptomatic during pregnancy, they may complicate its course $[2,3]$. At this time, the growth and behaviour of uterine leiomyomas during pregnancy cannot be predicted. The management of leiomyoma during pregnancy is medical, but, in rare circumstances, surgical intervention and myomectomy may be required [4].

L. Santos $\cdot$ M. João Nunes $\cdot$ I. Nery $\cdot$ M. Caetano $\cdot$ N. Assunção Department of Obstetrics and Gynaecology,

Hospital Dona Estefânia,

Lisbon, Portugal

L. Vicente

Department of Obstetrics and Gynaecology,

Hospital Torres Vedras,

Torres Vedras, Portugal

L. Santos $(\bowtie)$

Jardim Jacarandas 4.28.02 C 2 C,

1990-237 Lisboa, Portugal

e-mail: leonorsantos@yahoo.com

Tel.: +351-96-6631952

\section{Case report}

A 37-year-old woman, gravid 2, para 3 (a past history of a twin pregnancy with foetal death in utero at term and a vaginal delivery), came to the emergency room with a 6week pregnancy, complaining of moderate vaginal bleeding and pelvic pain. On examination, a prolapsed, pedunculated leiomyoma, measuring $4 \mathrm{~cm} \times 6 \mathrm{~cm}$ was detected. The complete blood count showed a haemoglobin concentration of $11.8 \mathrm{~g} / \mathrm{dl}$ and a haematocrit level of $33 \%$. Pelvic sonography showed a uterus with an embryo $10.5 \mathrm{~mm}$ in a craneo-caudal position and a prolapsed pedunculated leiomyoma of $41.5 \mathrm{~mm} \times 44.7 \mathrm{~mm}$ within the cervix in the vagina (Fig. 1).

Operative hysteroscopy was performed in an ambulatory setting. The procedure was done with a $5.5 \mathrm{~mm}$, continuous flow, hysteroscopy system with a 5-French working channel permitting the passage of a Versa Point bipolar device (Gynecare, Ethicon, Somerville, N.J., USA). We used a twizzle electrode for coagulating and cutting. We introduced the hysteroscope just inside the canal until the internal hole and then we sectioned the stalk. We kept the input pressure below $100 \mathrm{mmHg}$, using an electronic pump for irrigation and aspiration (Endomat, Karl Storz, Tuttlingen, Germany). Operating time was $20 \mathrm{~min}$. The leiomyoma measured $4 \mathrm{~cm} \times 6 \mathrm{~cm}$, with a $2 \mathrm{~cm}$ stalk. The histological examination confirmed the leiomyomatous characteristics of the tumour. The patient was discharged on the day after the procedure, asymptomatic and with the prescription of amoxicillin as a prophylactic antibiotic for 8 days.

The pregnancy progressed to term without further complications. She had a normal vaginal delivery with a normal labour at 38 weeks of gestation, and a healthy female infant was born, weighting $3.300 \mathrm{~g}$.

\section{Discussion}

Controversy persists among reports of myomectomy being performed during pregnancy. We describe the case of a 


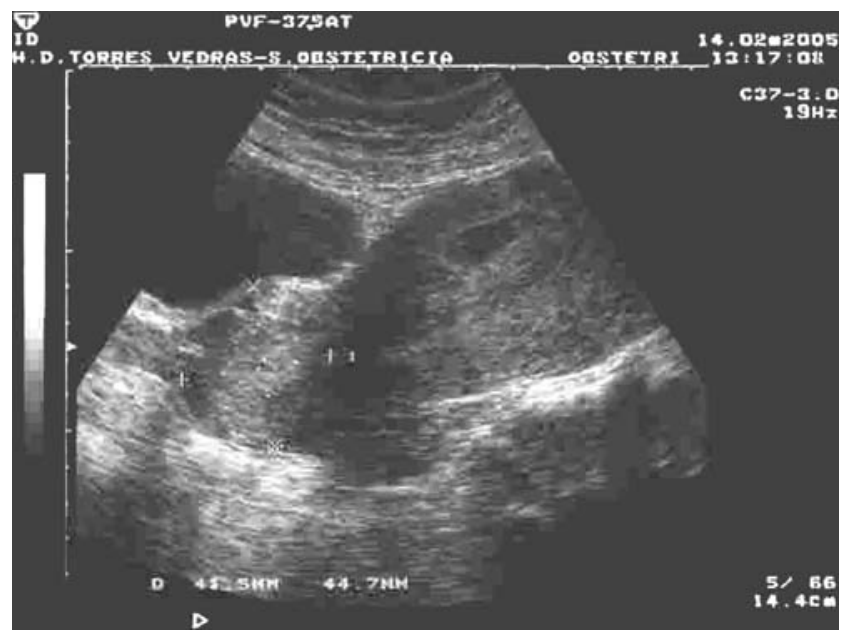

Fig. 1 Pelvic sonogram

successful myomectomy performed during the first trimester of pregnancy.

In this case surgical management of the leiomyoma was required, on the basis of the leiomyoma's characteristics and the presence of symptoms. Surgical resection of leiomyomas should be reserved for those pregnant women with symptomatic pedunculated leiomyomas with a small stalk [5].
With improvements in endoscopic surgical technology, most intracavitary leiomyomas can be resected via surgical hysteroscopy in an ambulatory setting in non-pregnant women. As the tumour protrudes completely into the vagina via a stalk, a hysteroscopic resection is by far the most cost- effective method for its removal.

In cases where conservative treatment cannot be chosen it seems that the risk of spontaneous abortion during pregnancy is not significantly increased when myomectomy is performed in carefully selected patients, according to the literature.

\section{References}

1. Fletcher MH, Frederick J (2005) Abdominal myomectomy revisited. Prog Obstet Gynaecol 16:277-286

2. Cooper NP, Okolo S (2005) Fibroids in pregnancy-common but poorly understood. Obstet Gynecol Surv 60:132-138

3. Oruc S, Karaer O, Kurtul O (2004) Coexistence of a prolapsed, pedunculated cervical myoma and pregnancy complications: a case report. J Reprod Med 49:575-577

4. Lolis DE, Kalantaridou SN, Makrydimas G, Sotidiaris A, Navrozoglou I, Zikopoulos K et al (2003) Successful myomectomy during pregnancy. Human Reprod 18:1699-1702

5. Phelan JP (1995) Myomas and pregnancy. Obstet Gynecol Clin North Am 22:80-85 